\title{
Preparation and characterization of activated carbon from wheat straw to remove2, 4-dichlorophenoxy acetic acid from aqueous solutions
}

\author{
Molla Tefera $^{\mathrm{a}^{*}}$ and Mengistu Tulu ${ }^{\mathrm{a}}$
}

${ }^{a}$ Department of Chemistry, University of Gondar, P. O. Box 196, Gondar, Ethiopia

\begin{tabular}{l} 
C H R O N I C L E \\
\hline Article history: \\
Received October 1, 2020 \\
Received in revised form \\
November 30, 2020 \\
Accepted January 4, 2021 \\
Available online \\
January 4, 2021 \\
\hline Keywords: \\
Activated carbon \\
Wheat straw \\
2,4-D, Adsorption
\end{tabular}

\section{Introduction}

Currently, water pollution is one of the most important environmental problems in the world. It may be contaminated by natural sources or by industrial effluents. ${ }^{1}$ Pesticides prevent or reduce loss of products caused by pests and can also improve yield as well as quality of agricultural products. The derivatives of urea, pyridazinone, phenoxy acetic acid, tryazin and group of chlorinated pesticides are most frequently types of pesticides found in water bodies. ${ }^{2}$ In spite of their extensive uses; pesticides are recognized as potential source of pollutants to soil and water due to their mobility and degradation and are serious concerns of health risks. ${ }^{3,4}$

2,4- dichlorophenoxy aceticacid (2,4-D) is a selective phenoxy herbicidecommonly used throughout the world to control broad-leaf weeds for the last 50 years due to its low cost, effectiveness even at low doses and good water solubility (Fig. 1). However, several reports have shown that 2,4-D is carcinogenic and mutagenic agent. Owing to its poor biodegradability, 2,4-D has been frequently detected in water bodies. There are several methods such as adsorption, photo-catalytic degradation, combined biological oxidation, advanced oxidation processes, aerobic degradation, coagulation, fluid extraction, and solid-phase extraction used for the removal of 2,4-D from water. Adsorptions of 2,4-D from aqueous solution using agricultural byproduct, wood and animal manure have been reported as

* Corresponding author.

E-mail address: mollatef2001@gmail.com, molla.tefera@uog.edu.et (M. Tefera)

(c) 2021 Growing Science Ltd. All rights reserved.

doi: $10.5267 /$ j.ccl.2021.1.002 
effective, economical and practical method ${ }^{5,6}$ Due to its high surface area and porosity caused by heterogeneous structures, activated carbon was found to be the most promising material for the removal of 2,4-D from contaminated water and waste water. ${ }^{7}$ The removal efficiency of adsorption process is mostly affected by various factors, including $\mathrm{pH}$, contact time, initial concentration of the contaminant, adsorbent dose and temperature. ${ }^{8}$<smiles>O=C(O)COc1ccc(Cl)cc1Cl</smiles>

Fig. 1. Chemical structure of 2,4- dichlorophenoxy acetic acid

Adsorption is a surface-based process in which adsorbate is held onto the surface of adsorbent by Van der Waals forces, electrostatic attraction and chemical bonding. Several authors have successfully studied variety of low-cost and locally available adsorbents such as wood, coconut, Jatropha Curcas, sugar cane bagasse, orange peels, tomato processing solid waste and macadamia nutshell ${ }^{9,10}$ for the removal of different types of pesticideslikeoxamyl ${ }^{11}$, chloropyriphos and cypermethrin ${ }^{12}$, carbofuran ${ }^{13}$, diazinon ${ }^{14}$ and phenoxyacid ${ }^{7}$ from water. Adsorption is the most efficient and promising approach in the removal of hazardous compounds from polluted waters. ${ }^{15}$ Thus, the aim of this study was to prepare activated carbons from wheat straw and to investigate optimum conditions for the removal of 2,4-D from aqueous solution.

\section{Results and Discussion}

\subsection{Characterization of activated carbon}

\subsubsection{Scanning electron microscope (SEM)}

Since adsorption is a surface phenomenon, the rate and the extent of adsorption of a given adsorbent are influenced by the physico-chemical characteristics (surface area, pore size and surface morphology.) of the adsorbent. Scanning electron microscope (SEM) was used to investigate the surface morphology of the adsorbents. The SEM images of AC before treatment and after treatment with $\mathrm{KOH}$ are given in Fig.2A and 2B, respectively. The image after treatment showed thick wall nonuniformly distributed onto the surface of activated carbon along with wider porosity and different shapes, indicating that the external surfaces of the adsorbent materials are full of cavities. Owing to this, the material to be adsorbed can be diffused to the cavities of AC.

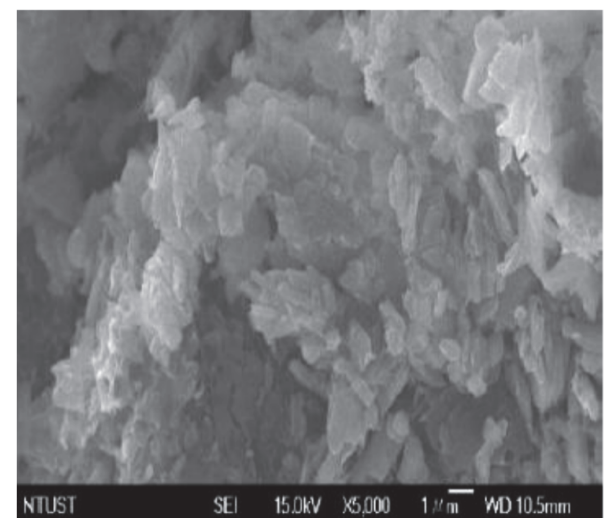

(A)



(B)

Fig. 2. SEM images before treatment (A) and after treatment (B) of $\mathrm{AC}$ with $\mathrm{KOH}$ 


\subsubsection{FTIR characterization of $A C$}

Fourier transform infrared (FTIR) spectroscopic analysis was used to study the surface chemistry of activated carbon (WSB) before and after adsorption of 2,4-D (Fig.3). Before adsorption, a sharp absorption band around $3420 \mathrm{~cm}^{-1}$ is assigned-OH groups. A band around $2950 \mathrm{~cm}^{-1}$ is attributed to the asymmetric $\mathrm{C}-\mathrm{H}$ stretching vibration of aliphatic acids, while a very weak peak observed around $2850 \mathrm{~cm}^{-1}$ may be ascribed to the symmetric $\mathrm{C}-\mathrm{H}$ stretching vibration of methyl groups. ${ }^{10,}{ }^{16}$ The absorption band located about $1597 \mathrm{~cm}^{-1}$ are assigned to the $\mathrm{C}=\mathrm{C}$ vibration in aromatic rings. The peaks between 1250 and $1111 \mathrm{~cm}^{-1}$ are associated with $\mathrm{C}-\mathrm{O}$ stretch.

After adsorption, there were change in peaks or spectra position after 2,4-D was adsorbed. For instance, strong broad bands at $3421 \mathrm{~cm}^{-1}$ corresponds to -OH group vibration, which was due to the overwhelming effect of hydrogen bonding on the $\mathrm{OH}$ groups. A peak around $1730 \mathrm{~cm}^{-1}$ may be assigned to the presence of carbonyl C-O group. The peak around $1597 \mathrm{~cm}^{-1}$ slightly shifted to $1624 \mathrm{~cm}^{-1} .{ }^{15}$ This shift in peak position and intensity may be due to the formation of chemical bond between functional groups present on wheat straw with the analyte. ${ }^{17}$



(A)

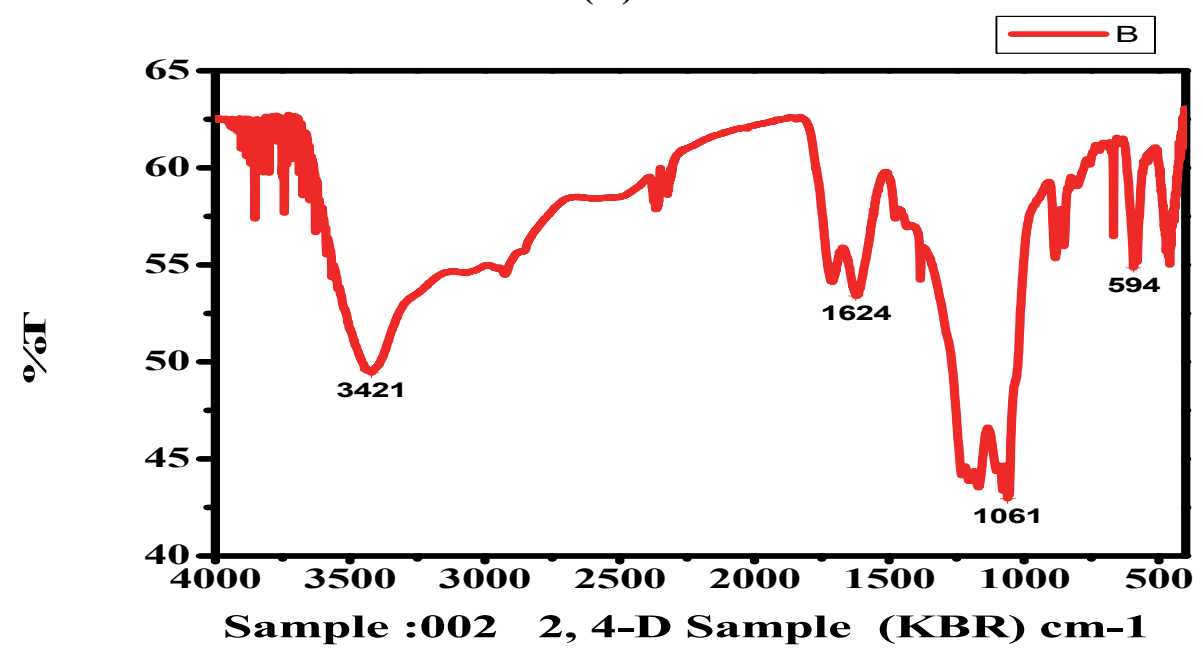

(B)

Fig. 3. FTIR spectra of wheat straw activated with $\mathrm{KOH}$ before (A) and after (B) 2, 4-D adsorption

\subsection{Proximate Analysis}

As it can be seen in Table 1, there are differences in moisture content, ash content, volatile matter, iodine number and $\mathrm{pH}$ of raw; acid activated (WSA) and base activated carbons (WSB). It was found that the moisture content, ash content and volatile matter decreased in the order of WSR $<$ WSA $<$ WSB. 
The basic activating agent $(\mathrm{KOH})$ significantly decomposed the tissue of carbon precursor and also created some new pores and voids, which increased the contact area between the activating agent and the carbon precursor. ${ }^{16}$ During activation step, volatile matter was released as gas and liquid products which evaporated off by leaving a material with high carbon content. ${ }^{17} \mathrm{High}$ ash content is undesirable for activated carbon since it reduces the mechanical strength of carbon and affects adsorptive capacity. However, the iodine number is maximum for WSB and minimum for WSR, which could be attributed to degradation of more extensive volatile matter, increased reaction of $\mathrm{KOH}$ and increased the release of $\mathrm{CO}_{2}$ in the presence of high porosity in the carbonsurface. ${ }^{18}$ Therefore, WSB has best sorption capacity towards 2,4-D. A similar trend has been reported in the literature. ${ }^{17,19}$

Proximate analysis clearly indicates that the activation process has successfully increased the iodine number and decreased the volatile matter, moisture and ash content. Therefore, wheat straw was a good precursor for the production of activated carbon with high removal efficiency. The $\mathrm{pH}$ of WSR, WSA and WSB was found to be 7.09, 6.96 and 7.02, respectively. Generally, $\mathrm{pH}$ of carbon between 6 and 8 is acceptable for most removal application such as sugar decolourization, water treatment, etc. ${ }^{20}$

Table 1. Physicochemical characteristics of raw wheat straw (WSR), acid activated wheat straw (WSA) and base activated wheat straw (WSB)

\begin{tabular}{cccc}
\hline Properties & $\boldsymbol{W S R}$ & $\boldsymbol{W S A}$ & $\boldsymbol{W S B}$ \\
\hline Moisture content (\%) & $9.08 \pm 0.40$ & $5.78 \pm 0.03$ & $4.12 \pm 0.06$ \\
Ash content (\%) & $13.71 \pm 0.47$ & $8.52 \pm 0.49$ & $5.53 \pm 0.50$ \\
Volatile matter (\%) & $37.45 \pm 0.03$ & $33.97 \pm 0.50$ & $20.81 \pm 0.50$ \\
Iodine No.(mg/g) & $92.24 \pm 0.05$ & $169.18 \pm 0.20$ & $194.29 \pm 0.050$ \\
\hline$p H$ & $7.02 \pm 0.03$ & $6.69 \pm 0.02$ & $7.1 \pm 0.03$ \\
\hline
\end{tabular}

\subsection{Effect of $p H$}

The $\mathrm{pH}$ is one of the most important parameters which significantly affects the adsorption of adsorbate on the adsorbent, because it affects adsorbent surface charge. The electrostatic interactions between adsorbent and adsorbate are controlled with $\mathrm{pH}$. The influences of $\mathrm{pH}$ on the adsorption of 2,4-D were studied at different $\mathrm{pH}$ values (2-10) at contact time of $25 \mathrm{~min}$, initial concentration of 10 $\mathrm{mg} / \mathrm{L}$ of $2,4-\mathrm{D}$, adsorbent dose (AC) of $1.0 \mathrm{~g}$ at $25^{\circ} \mathrm{C}$.

As it can be seen from Fig. 4A, the removal of 2,4-D decreased with increased $\mathrm{pH}$. High removal efficiency at lower $\mathrm{pH}$ is attributed to the formation of oxygen-containing species at the surface of activated carbon. In the $\mathrm{pH}$ range greater than $\mathrm{pKa}$ value $(2.73)$ of 2,4-D, the surface charge of 2,4-D in the aqueous solution is always negative and as a consequence the electrostatic repulsion force or diffusion of the 2,4-D ions at the surface of granular activated carbon was increased. A similar trend has also been reported in literature. ${ }^{8}$

\subsection{Effect of temperature}

The effect of temperature on the adsorption of $2,4-\mathrm{D}$ was studied by varying the temperature $\left(20^{\circ} \mathrm{c}-\right.$ $80^{\circ} \mathrm{C}$ ) at contact time of $25 \mathrm{~min}$, initial concentration of $10 \mathrm{mg} / \mathrm{L}$ of $2,4-\mathrm{D}$ and adsorbent dose (AC) of $1.0 \mathrm{~g}$. As shown in Fig. 4B, it was found that the removal efficiency of 2,4-D increased from $20^{\circ} \mathrm{C}$ to $60^{\circ} \mathrm{C}$, which may be attributed to the endothermic nature of adsorption of $2,4-\mathrm{D}$ onto AC. After $60^{\circ} \mathrm{C}$, the removal efficiency decreased, suggesting that adsorption process was carried out by releasing of activation energy and increasing the solubility and it was less retained by the adsorbent. ${ }^{21}$ 



Fig. 4. Effect of (A) $\mathrm{pH}$ and (B) temperature on the removal of 2,4-D

\subsection{Effect of adsorbent dose}

In the present study, the effect of adsorbent dose on the removal of 2,4-D (10 mg/L) from aqueous solution was determined by changing the doses from 0.1-1.4 $\mathrm{g}$ at the optimal conditions. As shown in Fig.5A, the removal efficiency of 2,4-D increased from 84.0 to $91.3 \%$ as the AC dose increased from 0.1 to $1.0 \mathrm{~g}$, which attributed to the availability of large surface area as well as abundant active sites entirely exposed for adsorption. While, decreased in adsorption after $1.0 \mathrm{~g}$ could be ascribed due to the fact that higher adsorbent dosage may cause aggregation, which resulted in decreasing the total surface area of adsorbent and increasing in the diffusional path length. ${ }^{22}$

\subsection{Effect of contact time}

Appropriate contact time can improve the treatment efficiency and provide cost-effective route for removal of chemical species. As can be seen from Fig.5B, the amount of 2,4-D adsorbed increased speedily in the first stage of adsorption, then slowly increased with contact time and almost remained constant above $30 \mathrm{~min}$. The rapid increment at the beginning of the process can be attributed to the availability of active sites on the exterior surfaces as well as the weak internal diffusion resistance during early adsorption stage. After saturation of those active sites, 2,4-D entered to the pores of the adsorbent with a slower rate to reach the equilibrium time ${ }^{23}$, which ascribed by an increase in repulsive forces due to the presence of adsorbed ions making the remaining sites more difficult to access. ${ }^{23}$ The percentage removal of 2,4-D at the optimal adsorbent time was around $90.6 \%$. Further increase in contact time did not bring any substantial improvement on the removal efficiency 

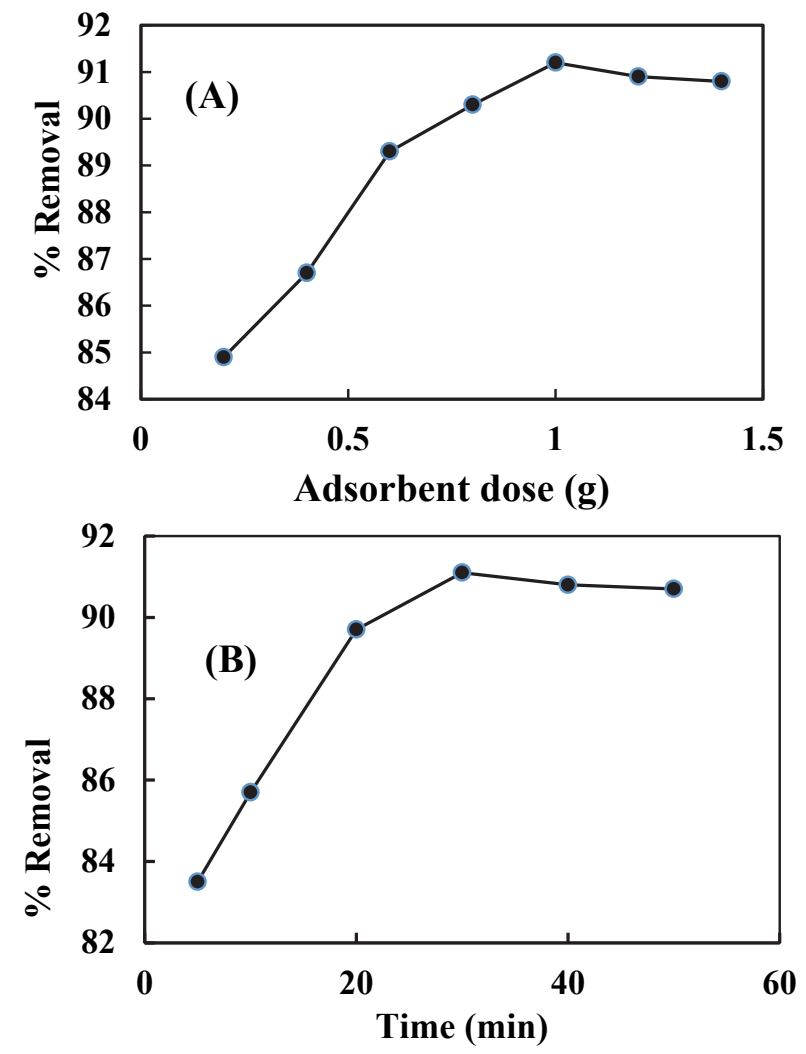

Fig. 5. Effect of (A) adsorbent dose and (B) contact time on the removal of 2,4-D

\subsection{Effect of initial concentration}

The effect of initial concentration of 2,4-D on the adsorption efficiency of AC was investigated in the concentration range of $1.0-25 \mathrm{mg} / \mathrm{L}$ at $1.0 \mathrm{~g}$ of $\mathrm{AC}$, temperature of $60^{\circ} \mathrm{C}, \mathrm{pH}$ of 4 and contact time of $30 \mathrm{~min}$. As shown in Fig.6, the amount of adsorbed 2,4-D increased until the initial concentration reached to $15 \mathrm{mg} / \mathrm{L}$ and then reaching a plateau with a relative slow rate. This is attributed to the utilization of all available active sites for adsorption of 2,4-D by increasing number of collisions with the adsorbent. ${ }^{11}$ However, the sites were saturated with increased 2,4 -D concentration.



Fig. 6. Effect of initial concentration of 2,4-D 


\subsection{Adsorption Isotherms}

As shown in Table 2, best fit was obtained for Langmuir isotherm model, which has a regression coefficient $\left(\mathrm{R}^{2}\right)$ of 0.996 as compared to Freundlich isotherm, $\mathrm{R}^{2}$ of 0.940 . Langmuir isotherm model was also expressed in terms of the dimensionless separation factor, $R_{L}$ and it was found to be 0.15 , indicating that the adsorption of 2,4-D on AC was favorable. Langmuir model assumes that all the available adsorption active sites are homogenous, the adsorbed species do not interact and a monolayer is formed during adsorption. ${ }^{24}$ However, the Freundlich constant $\mathrm{n}$ was found to be less than 1, which indicating that the adsorption of 2,4-D onto AC is not favorable physical process. ${ }^{11,22}$ Similar results have been reported in literature for the adsorption of 2,4-D from aqueous solution by activated carbon. 25,26

Table 2. Adsorption isotherm parameters for 2,4-D removal by activated carbon

\begin{tabular}{ccc}
\hline isotherms & Parameters & value \\
\hline \multirow{2}{*}{ Langmuir } & $\left.\mathrm{q}_{\mathrm{m}} / \mathrm{mg} / \mathrm{g}\right)$ & 1.015 \\
& $\mathrm{~b}(\mathrm{~L} / \mathrm{mg})$ & 0.367 \\
Freundlich & $\mathrm{R}^{2}$ & 0.996 \\
& $\mathrm{kf}(\mathrm{mg} / \mathrm{g}))$ & 0.974 \\
& $\mathrm{n}$ & 0.760 \\
\hline
\end{tabular}

\section{Conclusion}

A 2, 4-dichlorophenoxy acetic acid is widely used herbicide due to its low cost and good selectivity. It is toxic to broad-leafed plants, animals and humans; and it has poor biodegradability which leads to contaminate surface and ground water. In this study, a low-cost and easily available agricultural waste material (wheat straw) was employed for the removal of 2,4-D from aqueous solution. The removal efficiency of 2,4-D has been examined by varying parameters such as activated carbon dose, temperature, $\mathrm{pH}$ and contact time. Adsorption capacity of adsorbent increased with increasing initial concentration of 2,4-D, temperature, contact time and adsorbent dose until it reached to the optimal value. However, the percentage removal of 2,4-D decreased with increase in solution $\mathrm{pH}$. Due to high removal efficiency of activated carbon for 2,4-D from aqueous solutions at the optimal conditions, wheat straw is an alternative material and effective biosorbent for 2,4-D.

\section{Materials and Methods}

\subsection{Apparatus and instruments}

Drying oven (DHG- 9030, Japan), electronic balance (ESJ- 200-4, Japan), grinding mill, electrical furnace (91E, England), thermometer, heating mantle with stirrer, UV-Visible spectrophotometer (Perkin Elmer Lambda 950, UK), FT-IR (PerkinElmer, USA) spectrometer, field-emission scanning electron microscope (FESEM, ISM 6500F, JEOL, Japan), pH meter (model E 520, Switzerland), crucible and analytical balance $(0.001 \mathrm{~g})$ were the instruments used in this study.

\subsection{Chemicals and Reagents}

Potassium hydroxide $(0.1 \mathrm{M})$ and sulphuric acid $(0.1 \mathrm{M})$ were used for impregnation. Sodium hydroxide crystals $(0.1 \mathrm{M})$ and hydrochloric acid $(0.1 \mathrm{M})$ were used to adjust the $\mathrm{pH}$ of solution. Iodine crystal, potassium iodide, standard solution of iodine, standard sodium thiosulphate, 2,4-D (95\% purity) were also the chemicals used in this study. All chemicals and reagents used in the present study were of analytical grade. 


\subsection{General procedure}

\subsubsection{Sample collection and carbonization}

Wheat straw (WS) free from pesticide residue was collected from wheat farmland of Kulumsa agricultural research center, Arsi Zone, Ethiopia. The wheat samples were prepared first by washing thoroughly with distilled water to avoid adhered impurities. Then, the dried wheat straws were pulverized and sieved to get appropriate sized adsorbent.

$50 \mathrm{~g}$ of wheat straw sample was weighed into a crucible and introduced into furnace with a limited supply of air at temperature of $330^{\circ} \mathrm{C}$ for $40 \mathrm{~min}$. The heated wheat straw was cooled at room temperature and transferred into a beaker filled with distilled water. The excess water dried in oven at $120^{\circ} \mathrm{C}$ to constant weight for $24 \mathrm{~h}$. This process was repeated until substantial amount of carbonized samples were obtained. The resulting sample labeled as wheat straw raw sample (WSR) and stored in sealed plastic container for further activation.

The water samples were collected from Boneya River and Gonde River, Arsi Zone, Ethiopia in cleaned polyethylene bottles and filtered through a $0.45 \mathrm{~mm}$ pore size nylon filter. The amount of 2,4D recovered was determined using UV-Vis spectrophotometer at a wavelength of $430 \mathrm{~nm} .{ }^{27,28}$

\subsubsection{Activation of the carbonized samples}

A $20 \mathrm{~g}$ of the carbonized sample (WSR) was mixed with $40 \mathrm{~mL}$ of $0.1 \mathrm{M} \mathrm{KOH}$ and $0.1 \mathrm{M} \mathrm{H}_{2} \mathrm{SO}_{4}$ for activation. The content of the beaker was carefully homogenized and allowed to stand for $24 \mathrm{~h}$. The activated sample was diluted with $200 \mathrm{~mL}$ of distilled water to rinse-off activating agents. The process of washing was repeated until the $\mathrm{pH}$ failed between 6.5 and 7.05. The activated carbon oven dried at $120{ }^{\circ} \mathrm{C}$ for $2 \mathrm{~h}$ was sieved to obtain fine powdered wheat straw activated carbons (WSA and WSB). The activated carbons were stored in a sealed plastic container until used for further analysis.

The prepared activated carbons were characterized by proximate analysis, Fourier transform infrared (FTIR) and scanning electron microscopy (SEM). The effects of various operational parameters which affect adsorption efficiencies of activated carbons were also investigated. The adsorption process was tested by Langmuir and Freundlich isotherms models.

\subsubsection{Proximate analysis}

The proximate analyses as (ash content, moisture, volatile matter, etc) help to determine the distribution of products obtained when activated carbon is heated under specified conditions. Most often it used for characterizing a material in connection with their utilization. Proximate analysis was carried out using gravimetric method. ${ }^{29}$

\subsubsection{Iodine number test}

The adsorption capacity and the quality of activated carbon can be determined with iodine number. It also measures the micropores content of activated carbon which are created during activation and the activity level of the adsorbent. ${ }^{30}$ The iodine number of activated carbon were obtained by adopting the procedure of Vunain et al. ${ }^{19}$ Briefly, a $0.5 \mathrm{~g}$ of activated wheat straw was mixed with $10 \mathrm{~mL}$ of $0.1 \mathrm{M}$ $\mathrm{HCl}$. Then, $100 \mathrm{~mL}$ of iodine stock solution prepared from $2.7 \mathrm{~g} / \mathrm{L}$ of iodine crystal and $4.19 \mathrm{~g} / \mathrm{L}$ of potassium iodide was added and agitated with high speed using an electric shaker for $50 \mathrm{~min}$. The mixture was filtered through Whatman (No. 41) filter paper and an aliquot portion $(20 \mathrm{~mL})$ was titrated with $0.1 \mathrm{M}$ sodium thiosulphate using $2 \mathrm{~mL}$ starch as an indicator until a colorless solution was produced. ${ }^{17,31}$

\subsubsection{Moisture and ash content}

The moisture content was determined by drying $10 \mathrm{~g}$ of raw (WSR) and activated carbons (WSA and WSB) in an oven continuously at $100{ }^{\circ} \mathrm{C}$ for an hour. Then, the carbon was cooled and reweighed again. Similarly, the ash content was also determined by heating the wheat straw and activated carbon 
to $550{ }^{\circ} \mathrm{C}$ for $8 \mathrm{~h}$ until a white ash was obtained. The results of the proximate analyses of the wheat straw and activated carbons are given in Table 1.

\subsubsection{Adsorption and desorption experiments}

For adsorption experiments, a definite amount of adsorbent was added to the standard 2,4-D solutions prepared using distilled water and then subjected to various adsorption conditions like $\mathrm{pH}$, temperature and contact time. At the end of the experiment, the solution was filtered through a filter paper and the concentration of remaining 2,4-D in liquid phase was analyzed with UV-Vis spectrophotometer. The amount of 2, 4-D adsorbed on the material, $\mathrm{q}_{\mathrm{e}}(\mathrm{mg} / \mathrm{g})$ was calculated as:

$$
q e=v \frac{(C o-C e)}{m}
$$

where $\mathrm{Co}$ and $\mathrm{Ce}$ are the initial and equilibrium 2,4-D concentration $(\mathrm{mg} / \mathrm{L})$, respectively, $\mathrm{q}_{\mathrm{e}}$ is the amount of 2,4-D adsorbed $(\mathrm{mg} / \mathrm{g}), \mathrm{m}$ is the mass of the adsorbent $(\mathrm{g}), \mathrm{v}$ is the volume of the solution (L).

The percentage of 2,4-D removed was calculated using the equation. ${ }^{32}$

$$
\% \text { removal }=\frac{c o-c e}{c o} \times 100
$$

The $\mathrm{pH}$ level is one of the most important parameters for determining the adsorption of pesticides from aqueous solutions. The effect of solution $\mathrm{pH}$ on the adsorption of 2,4-D was investigated by varying the $\mathrm{pH}$ from 2 to 10 .

The effect of adsorbent dose was studied by varying the dose of activated carbon (0.1-1.4 g). The experiment was carried out by measuring $10 \mathrm{mg} / \mathrm{L}$ of 2,4-D solution in to a $100 \mathrm{~mL}$ conical flask and the required adsorbent dose was transferred into this conical flask followed by agitation for $20 \mathrm{~min}$. After the mixture was filtered through a Whatman filter paper (No. 41) and the filtrate was used for spectrophotometric test. Finally, the concentration of the residual pesticide remaining in the solution was determined using UV-Vis spectrophotometer.

Effect of contact time is very important to determine maximum amount of pesticide adsorption. In this study, $1.0 \mathrm{~g}$ of adsorbent was added to $20 \mathrm{~mL}$ of $10 \mathrm{mg} / \mathrm{L}$ of 2,4-D solution in a $100 \mathrm{~mL}$ conical flask and the solution was stirred with a magnetic stirrer in a water bath at $25^{\circ} \mathrm{C}$ at different contact time $(5-60 \mathrm{~min})$. The mixture was filtered immediately through a Whatman filter paper and the concentration of the remaining residue in solution was determined using UV-Vis spectrophotometer.

\subsubsection{Adsorption isotherms}

Adsorption isotherms gives qualitative information about the nature of solute-surface interaction as well as the specific relation between the concentration of adsorbate and its degree of accumulation onto the surface at a specified temperature. ${ }^{24}$ In the present study, equilibrium adsorption data were analyzed using the Langmuir and Freundlich isotherm models. The results of isotherms analyses were used to describe the experimental adsorption data, and result which provided a better correlation coefficient $\left(\mathrm{R}^{2}\right)$ was chosen to describe the experimental adsorption data.

The Langmuir isotherm is valid for monolayer adsorption onto a surface containing a finite number of identical sites. The model assumes that adsorption occurs uniformly on the active sites of the adsorbent, and once an adsorbate occupies a site, no further adsorption can take place at that site. ${ }^{24}$ The Langmuir isotherm is given by:

$$
\frac{C e}{q_{e}}=\frac{1}{q_{m} b}+\left(\frac{1}{q m}\right) C e .
$$


where $\mathrm{q}_{\mathrm{e}}(\mathrm{mg} / \mathrm{g})$ and $\mathrm{C}_{\mathrm{e}}(\mathrm{mg} / \mathrm{L})$ are the equilibrium amount adsorbed per unit mass of adsorbate and equilibrium concentration of the adsorbate, respectively, $\mathrm{q}_{\mathrm{m}}$ is the monolayer adsorption capacity of the $\mathrm{AC}, \mathrm{b}(\mathrm{L} / \mathrm{mg})$ is Langmuir constant or adsorption coefficient for binding of adsorbate on the adsorbent sites.

The affinity between the adsorbate and adsorbent can be expressed in terms of the dimensionless separation factor $(\mathrm{RL})$, which is given as follows:

$$
R_{L}=\frac{1}{1+K_{L}+C o}
$$

where $\mathrm{C}_{\mathrm{o}}$ is the initial adsorbate concentration in the solution $(\mathrm{mg} / \mathrm{L})$. If the value of $\mathrm{R}_{\mathrm{L}}$ is between 0 and 1, the adsorption is favourable, while if $R_{L}=0$ and $R_{L}>1$ indicating that the adsorption is irreversible and unfavorable adsorption isotherms, respectively. ${ }^{11,22}$

Freundlich isotherm can be applied to non-ideal adsorption on heterogeneous surfaces as well as multilayer adsorption. ${ }^{31}$ The linear form of Freundlich equation is expressed as:

$$
\log q_{e}=\log k_{f}+\frac{1}{n} \log C e,
$$

where, $\mathrm{kf}(\mathrm{mg} / \mathrm{g})$ and $1 / \mathrm{n}(\mathrm{g} / \mathrm{L})$ are the Freundlich constants related to adsorption capacity and intensity of adsorption, respectively.

\subsubsection{Method validation}

The reliability of analytical method was evaluated by spiking known concentrations of 2,4-D standards (10 and $15 \mathrm{mg} / \mathrm{L}$ ) to run-off water (Boneya and Gonde rivers) from agricultural fields sprayed with 2,4-D. The percentage of recovery values for 2,4-D removal were found in range of 99.86 to $101.7 \%$, which indicated the good accuracy of the used method. Therefore, the method was applicable for the determination 2,4-D in water samples.

\section{References}

1. Getachew T., Hussen A., \& Rao V. (2015) Defluoridation of water by activated carbon prepared from banana (Musa paradisiaca) peel and coffee (Coffea arabica) husk. Int. J. Sci. Environ. Technol., 12(6) 1857-1866.

2. Ninkovic B., Petrovic R., \& Lausevic D. (2010) Removal of organochlorine pesticides from water using Virgin and regenerated granular activated carbon. J. Serbian Chem. Soc., 75(4) 565-573.

3. Aminu, S., Gimba E., Kagbu J., Turoti M., Itodo U., \& Sariyya I. (2010) Sorption efficiency study of pesticide adsorption on granulated activated carbon from groundnut shell using GC/MS. Elec. J. Env. Agri. Food Chem., 9 (7) 1222-1231.

4. Li J., Li Y., \& Lu J. (2009) Adsorption of herbicides 2,4-D and acetochlor on inorganic-organic bentonite. Appl. Clay Sci. 46 (3) 314-318.

5. Rojas R., Vanderlinden E., Morillo J., Usero J., \& El Bakouri H. (2014) Characterization of sorption processes for the development of low-cost pesticide decontamination techniques. Sci. Total Environ., 488 (1) 124-135.

6. Trivedi N., Kharkar R., \& Mandavgane S. (2019) 2,4-Dichlorophenoxyacetic acid adsorption on adsorbent prepared from groundnut shell: Effect of preparation conditions on equilibrium adsorption capacity. Arabian J. Chem., 12 (8) 4541-4549.

7. Derylo-Marczewska A., Blachnio M., Marczewski A., Swiatkowski A., \& Tarasiuk B. (2010) Adsorption of selected herbicides from aqueous solutions on activated carbon. J. Therm. Anal. Calorim., 101 (3) 785-794. 
8. Dehghani M., Nasseri S., \& Karamimanesh M. (2014) Removal of 2,4-Dichlorophenolyxacetic acid $(2,4-D)$ herbicide in the aqueous phase using modified granular activated carbon. J. Environ. Health Sci. Eng., 12 (28) 1-10.

9. Elmouwahidi A., Bailon-García E., Perez-Cadenas A., Maldonado-Hodar F., \& Carrasco-Marin F. (2017) Activated carbons from $\mathrm{KOH}$ and $\mathrm{H}_{3} \mathrm{PO}_{4}$-activation of olive residues and its application as supercapacitor electrodes. Electrochimica Acta, 229 (7) 219-228.

10. Saygili H., \& Guzel F. (2016) High surface area mesoporous activated carbon from tomato processing solid waste by zinc chloride activation: process optimization, characterization and dyes adsorption. J. Clean. Prod., 113(9) 995-1004.

11. Mohammad S., \& Ahmed S. (2017) Preparation of environmentally friendly activated carbon for removal of pesticide from aqueous media. Int. J. Chem. Technol. 8 (2) 121-132.

12. Okeola F., Odebunmi E., Nwosu F., Abu T., Idiagbonya O.; Amoloye M., Onifade F., \& Abdulmummeen A. (2017) Remediation of Aqueous Solution of Cypermethrin and Chlorpyriphos Using Derived Adsorbent from Jatropha Curcas, J. Appl. Sci. Environ. Manage., 21(1) 40-46.

13. Chang K., Lin J., \& Chen S. (2011) Adsorption studies on the removal of pesticides (carbofuran) using activated carbon from rice straw agricultural waste. Int. J. Agric. Biol. Eng., 5(4) 210-213

14. Moussavi G., Hosseini H., \& Alahabadi A. (2013) The investigation of diazinon pesticide removal from contaminated water by adsorption onto $\mathrm{NH}_{4} \mathrm{Cl}$-induced activated carbon. Chem. Eng. J., 214 (1), 172-179.

15. Gupt V., Gupta B., Rastogi A., Agarwal S., \& Nayak A. (2011) Pesticides removal from waste water by activated carbon prepared from waste rubber tire. Water Res., 45(13) 4047-4055.

16. Adowei P., Horsfall J., \& Spiff A. (2012) Adsorption of methyl red from aqueous solution by activated carbon produced from cassava (Manihotesculenta Cranz) peel waste. Innov. Sci. Eng., 2(2) 24-33.

17. Bello O., Adegoke K., \& Akinyunni O. (2017) Preparation and characterization of a novel adsorbent from Moringa oleifera leaf. Appl. Water Sci., 7(3) 1295-1305.

18. Mopoung S., Moonsri P., Palas W., \& Khumpai S. (2015) Characterization and properties of activated carbon prepared from Tamarind seeds by $\mathrm{KOH}$ activation for $\mathrm{Fe}(\mathrm{III})$ adsorption from aqueous solution. The Sci. World J., 1(1) 1-9.

19. Vunain E., Kenneth D., \& Biswick T. (2017) Synthesis and characterization of low-cost activated carbon prepared from Malawian b, aobab fruit shells by $\mathrm{H}_{3} \mathrm{PO}_{4}$ activation for removal of $\mathrm{Cu}$ (II) ions: equilibrium and kinetics studies. Appl. Water Sci., 7(8) 4301-4319.

20. Ravichandran P., Sugumaran P., Seshadri S., \& Basta A. (2018) Optimizing the route for production of activated carbon from Casuarina equisetifolia fruit waste. Royal Soc. Open Sci., 5(7) 1-12.

21. El Ouardi M., Alahiane S., Qourzal S., Abaamrane A., Assabbane A., \& Douch J. (2013) Removal of carbaryl pesticide from aqueous solution by adsorption on local clay in Agadir. Am. J. Chem., 4(7) $72-79$.

22. Ozsin G., Kilic M., Apaydın V., \& Putun A. (2019) Chemically activated carbon production from agricultural waste of chickpea and its application for heavy metal adsorption: equilibrium, kinetic, and thermodynamic studies. Appl. Water Sci., 9(3) 1-14.

23. Fu L., Zhang G., Wang S., Zhang L., \& Peng J. (2017) Modification of activated carbon via grafting polyethyleneimine to remove amaranth from water. Appl. Water Sci., 7(8) 4247-4254.

24. Alghamdi A., Al-Odayni A., Saeed W., Al-Kahtani A., Alharthi F., \& Aouak T. (2019) Efficient adsorption of Lead (II) from aqueous phase solutions using polypyrrole-based activated carbon. Mater., 12(12) 2-16.

25. Hameed B., Salman J., \& Ahmad A. (2009) Adsorption isotherm and kinetic modeling of 2,4-D pesticide on activated carbon derived from date stones. J. Hazard. Mater., 163(1) 121-126.

26. Bazrafshan E., Mostafapour F., Faridi H., Farzadkia M., Sargazi S., \& Sohrabi A. (2013) Removal of 2,4-Dichlorophenoxyacetic Acid (2, 4-D) from aqueous environments using single-walled carbon nanotubes. Health Scope., 2 (1) 39-46. 
27. Daundkar B., Mavle R., Malve, K., \& Krishnamurthy R. (2007) Spectrophotometric and TLC detection reagent for the insecticides dichlorvos (DDVP) and diptrex (Trichlorfon), and their metabolites, in biological tissues. J. Planar Chromat., 20 (3) 217-219.

28. Gupta V., \& Suhas S. (2009) Application of Low-Cost Adsorbents for Dye Removal. J. Environ. Manage., 90 (8) 2313-2326.

29. Trivedi, N., Kharkar, R., \& Mandavgane, S. (2016) Utilization of cotton plant ash and char for removal of 2,4-dichlorophenoxyacetic acid. Resource-Efficient Technol., 2, 39-46.

30. Saka C. (2012) BET, TG-DTG, FT-IR, SEM, iodine number analysis and preparation of activated carbon from acorn shell by chemical activation with $\mathrm{ZnCl}_{2}$. J. Anal. Appl. Pyrol., 95 (3) 21-24.

31. Omidi, F., Behbahani, M., Abandansari, H., Sedighi, A., \& Shahtaheri, S. (2014) Application of molecular imprinted polymer nanoparticles as a selective solid phase extraction for preconcentration and trace determination of 2,4-dichlorophenoxyacetic acid in the human urine and different water samples. J. Environ. Health Sci. Eng. 12 (1) 3-6.

32. Regti A., Laamari, M., Stiriba, S., \& El Haddad, M. (2017) The potential use of activated carbon prepared from Ziziphus species for removing dyes from waste waters. Appl. Water Sci., 7 (7) 40994108.

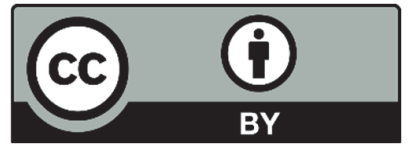

(C) 2021 by the authors; licensee Growing Science, Canada. This is an open access article distributed under the terms and conditions of the Creative Commons Attribution (CC-BY) license (http://creativecommons.org/licenses/by/4.0/). 